\title{
c-FLICE inhibitory protein expression inhibits T-cell activation
}

\author{
T-S Tai ${ }^{1,2}$, L-W Fang ${ }^{2,3}$ and M-Z Lai ${ }^{\star, 1,2,3,4}$ \\ ${ }^{1}$ Graduate Institute of Immunology, National Taiwan University, Taipei, Taiwan, \\ ROC \\ 2 Institute of Molecular Biology, Academia Sinica, Taipei, Taiwan, ROC \\ ${ }^{3}$ Graduate Institute of Life Science, National Defense Medical Center, Taipei, \\ Taiwan, ROC \\ ${ }^{4}$ Graduate Institute of Microbiology and Immunology, National Yang-Ming \\ University, Taipei, Taiwan, ROC \\ * Corresponding author: M-Z Lai, Institute of Molecular Biology, Academia \\ Sinica, Nankang, Taipei, 11529, Taiwan, ROC. Tel: + 88622789 9236; \\ Fax: + 88622782 6085; E-mail: mblai@ccvax.sinica.edu.tw
}

Received 30.1.03; revised 03.7.03; accepted 30.7.03; published online 29.8.03 Edited by S Nagata

\begin{abstract}
Cellular FLICE-inhibitory protein (c-FLIP) inhibits death receptor-mediated apoptosis by specific interaction with FADD and procaspase-8, and may thus interfere with activation events mediated by FADD and caspase-8. Recent studies, however, suggest that C-FLIP also transmits activation signals. The role of $c$-FLIP on T-cell activation was examined here using several transgenic mice with variable c-FLIP expression. In all c-FLIP-transgenic mice, Fasmediated apoptosis and in vitro activation-induced T-cell death were suppressed, and T-cell proliferation and IL-2 production were inhibited. c-FLIP transgene also promoted in vivo thymocyte death. Higher c-FLIP transgene expression was correlated with a more profound suppression of T-cell activation and a prominent disturbance in mature thymocyte development. There was no evidence of increased activation and proliferation in all c-FLIP-transgenic $T$ cells examined. Instead, suppression of T-cell activation in C-FLIP-transgenic $T$ cells could be a combinatory effect of FADD/caspase-8dependent signals and C-FLIP-specific activities.

Cell Death and Differentiation (2004) 11, 69-79. doi:10.1038/ sj.cdd. 4401316

Published online 29 August 2003

Keywords: c-FLIP; FADD; caspase-8; Fas; activation signal
\end{abstract}

Abbreviations: $A I C D$, activation-induced cell death; $D E D$, death effector domain; DR, death receptor; ERK, extracellular signalregulated kinase; FLIP, FLICE-like inhibitory protein; MAPK, mitogen-activated protein kinase

\section{Introduction}

Engagement of death receptors (DRs) leads to formation of death receptor complexes first through the recruitment of FADD to DR, followed by the association of procaspase- 8
(FLICE) with FADD due to interactions between the death effector domains (DEDs) of FADD and procaspase-8. The processing of procaspase- 8 at the DR complexes generates caspase-8, which then cleaves other procaspases to produce a panel of effector caspases for apoptosis execution. ${ }^{1,2}$ Cellular FLICE-inhibitory protein (c-FLIP) specifically regulates the DR apoptotic process. ${ }^{3-9} \mathrm{C}$-FLIP is expressed in both a long-form (c-FLIP $\mathrm{L}_{\mathrm{L}}$ ) and a short-form (c-FLIP ) $_{\mathrm{S}}$ due to alternative splicing. The DEDs of $c-F_{L} P_{L}$ and $c-F L I P_{S}$ interact with the DEDs of FADD and procaspasse-8. Through the binding of c-FLIP to FADD and procaspase-8 at the DR complexes, C-FLIP presumably prevents the processing of procaspase-8 and inhibits downstream apoptotic events. ${ }^{10,11}$

An intriguing issue regarding the physiological function of the DR apoptotic cascade is the involvement of FADD and caspase-8 in T-cell activation. ${ }^{12} \mathrm{~T}$ cells from FADD-deficient chimeric mice and dominant-negative FADD-transgenic mice display profound inhibition of proliferation. ${ }^{13-20} \mathrm{~T}$-cell activation is reported to stimulate caspase- 8 and suppression of caspase-8 prevents T-cell activation. ${ }^{21,22}$ More recently, caspase-8 mutation in human and mouse was linked to defective lymphocyte activation and immunodeficiency. ${ }^{23-25}$ These results suggested that FADD and caspase- 8 are involved in the activation of naïve $T$ cells, yet the activation signals mediated by $\mathrm{FADD}^{17}$ and caspase-8 remain largely unknown.

It was thought that overexpression of C-FLIP, through binding to FADD and procaspase-8, must generate phenotypes similar to mice with inactivated FADD or caspase-8. However, different effects on T-cell activation were observed with mice overexpressing c-FLIP. ${ }^{26,27}$ In one group, T-cell activation was not affected by expression of c-FLIP in vivo. ${ }^{26}$ In another study, C-FLIP-transgenic $T$ cells displayed increased proliferation when stimulated with low concentrations of anti-CD3, and decreased proliferation when activated with high concentrations of anti-CD3 ${ }^{27}$ Activation of extracellular signal-regulated kinase (ERK) and NF- $\kappa$ B and IL-2 production were also found to increase in the same c-FLIP-transgenic $T$ cells. ${ }^{28}$ For the latter observation, it was proposed that FADD participates in T-cell activation by the recruitment of c-FLIP and c-FLIP-associated signaling molecules, ${ }^{10}$ and failure to recruit c-FLIP in the absence of functional FADD leads to Tcell inactivation.

In this study, we generated c-FLIP-transgenic mice to study the exact effect of c-FLIP overexpression on T-cell activation. Fas-induced apoptosis and in vitro activation-induced cell death (AICD) were inhibited in c-FLIP-transgenic mice. T-cell proliferation and IL-2 production were suppressed in all CFLIP-transgenic mice. At different concentrations of TCR stimulants, we failed to detect any increase in proliferation and IL-2 production in T cells from all c-FLIP-transgenic mice. Our results do not support a direct activation role of c-FLIP in T-cell activation. We found that C-FLIP also transmitted signals independent of FADD and caspase-8. Together with c-FLIP- 
mediated inactivation of FADD and caspase-8, c-FLIP overexpression effectively inhibited T-cell activation.

\section{Results}

\section{Variable expression of c-FLIP transgene}

Human C-FLIP $\mathrm{L}_{\mathrm{L}}$ was subcloned into the $\mathrm{p} 1017$ vector with the Ick proximal promoter or into the CD2 cassette with the CD2 locus control region ${ }^{29}$ (Figure 1a). Genomic incorporation of

\begin{tabular}{l|c|c|} 
a \\
XhoI \\
\hline CD2 promoter(5kb) & FLIP (1.6kb) & CD2 LCR(5.5kb) \\
\hline & $\overrightarrow{5^{\prime}} 1.4 \mathrm{~kb}$ & $\overrightarrow{3^{\prime}}$
\end{tabular}

\begin{tabular}{|c|c|c|}
\hline \multicolumn{3}{|l|}{$\stackrel{\text { NotI }}{\longmapsto}$} \\
\hline Lck promoter(3.2kb) & FLIP (1.6kb) & hGH(2.1kb) \\
\hline
\end{tabular}

b

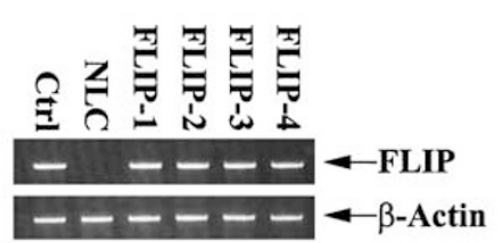

C

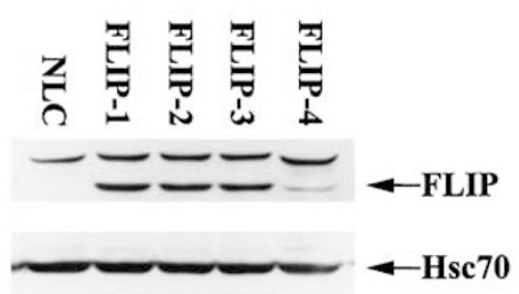

Figure 1 Transgenic expression of $c$-FLIP in $T$ cells. (a) Schematic representation of the Ick-c-FLIP $P_{L}$ and $C D 2-c-F L I P_{L}$ transgene. $c$-FLIP was subcloned into p1017 vector and CD2 cassettes. Arrows indicate the location of the transgenic-specific PCR primers. (b) PCR analysis of c-FLIP transgene integration. DNA prepared from the tail of 5-week-old CD2-c-FLIP transgenic mice and normal littermate controls (NLC) were amplified using transgenespecific PCR primers. The PCR products were resolved using agarose gels. FLIP-1 was produced from the C57BL/6 strain of mice, while FLIP-2, FLIP-3, and FLIP-4 were generated from the FVB strain of mice. (c) Expression of c-FLIP proteins in transgenic mice. The expression of c-FLIP proteins in thymocytes from the same four c-FLIP transgenic lines in (b) was determined by immunoblots transgenic $c-F L I P_{L}$ was detected by $P C R$ in mouse-tail DNA using lck-c-FLIP $P_{L}$ or CD2-c-FLIP $P_{L}$-specific primers (Figure 1b, not shown for Ick-c-FLIP $\mathrm{L}_{\mathrm{L}}$-transgenic mice). Transgenic C-FLIP $P_{L}$ protein expression was readily detectable in transgenic thymocytes due to the low expression of endogenous cFLIP (Figure 1c). The expression level of c-FLIP varied between different transgenic lines. Based on the expression levels of $\mathrm{c}$-FLIP, the $\mathrm{C}-\mathrm{FLIP}_{\mathrm{L}}$-transgenic mice were classified as either high-expression (represented by FLIP-1, FLIP-2, and FLIP-3 in Figure 1c) or low-expression (represented by FLIP-4 in Figure 1c). FLIP-1 was generated from the C57BL/6 strain of mice, while FLIP-2, FLIP-3, and FLIP-4 were produced from the FVB strain of mice. We generated a total of nine independent transgenic mouse lines. All results described below are from CD2-C-FLIP $\mathrm{L}_{\mathrm{L}}$-transgenic mice. Nearly identical results were observed with lck-c-FLIP $\mathrm{L}^{-}$ transgenic mice.

Thymus from c-FLIP-transgenic mice were smaller than their normal littermate control (NLC) mice in FVB strain (Table 1). Thymus size and total thymocyte number were affected to a greater degree in high c-FLIP-expressing transgenic mice than low c-FLIP-expressing mice. The extent of reduction in total thymocyte number seemed to correlate with the expression level of c-FLIP.

\section{Normal in vivo AICD and suppressed in vitro AICD in FLIP-transgenic $\mathbf{T}$ cells}

Regardless of the expression level, transgenic c-FLIP suppressed cell death triggered by anti-Fas antibody, but not cell death induced by dexamethasone or etoposide (Figure 2a, data not shown for etoposide). The in vivo AICD was determined by the deletion of the $\mathrm{V} \beta 3$ population, through the presence of endogenous superantigen mtv6 in BALB/c mice. Breeding of c-FLIP-transgenic mice (in C57BL/6 background) to BALB/c resulted in the deletion of $\mathrm{V} \beta 3^{+} \mathrm{T}$ cells (Figure 3). The deletion of $\mathrm{V} \beta 3^{+} \mathrm{T}$ cells in $\mathrm{C} 57 \mathrm{BL} / 6 \times \mathrm{BALB} / \mathrm{c}$ mice was not rescued by the presence of $c$-FLIP transgene. $\mathrm{V} \beta 6^{+} \mathrm{T}$-cell population, not affected by endogenous superantigen in C57BL/6 and BALB/c mice, was nearly identical in $\mathrm{C} 57 \mathrm{BL} / 6 \times \mathrm{BALB} / \mathrm{c}$ mice with or without the c-FLIP transgene (Figure 3). The deletion of autoreactive $\mathrm{T}$ cells indicates that the c-FLIP transgene did not prevent in vivo AICD.

We next examined whether in vitro AICD, known to be Fasmediated, ${ }^{30-33}$ was affected by FLIP transgene. NLC thymocytes stimulated with anti-CD3 underwent apoptosis, yet c-

Table 1 Cell number of thymocytes and subpopulations in NLC and c-FLIP-transgenic mice ${ }^{a}$

\begin{tabular}{|c|c|c|c|c|}
\hline & \multicolumn{2}{|c|}{ FLIP-high (in $10^{7}$ ) } & \multicolumn{2}{|c|}{ FLIP-Iow (in 107) } \\
\hline & NLC $(n=6)$ & FLIP $(n=6)$ & $\operatorname{NLC}(n=4)$ & FLIP $(n=4)$ \\
\hline $\begin{array}{l}\text { Total } \\
\text { CD4 }^{-} \mathrm{CD}^{-} \\
\mathrm{CD}^{+} \mathrm{CD}^{+} \\
\mathrm{CD}^{+}{ }^{+} \mathrm{CD}^{-} \\
\mathrm{CD}^{-}{ }^{-} \mathrm{CD}^{+}\end{array}$ & $\begin{array}{c}10.59 \pm 2.12 \\
0.27 \pm 0.07 \\
8.42 \pm 1.99 \\
1.54 \pm 0.14 \\
0.36 \pm 0.09\end{array}$ & $\begin{array}{l}4.91 \pm 1.89 \\
0.11 \pm 0.04 \\
4.03 \pm 1.45 \\
0.59 \pm 0.37 \\
0.18 \pm 0.08\end{array}$ & $\begin{array}{l}9.26 \pm 1.09 \\
0.17 \pm 0.07 \\
7.28 \pm 0.53 \\
1.48 \pm 0.49 \\
0.32 \pm 0.09\end{array}$ & $\begin{array}{l}7.96 \pm 1.02 \\
0.17 \pm 0.08 \\
6.34 \pm 0.50 \\
1.19 \pm 0.37 \\
0.25 \pm 0.09\end{array}$ \\
\hline
\end{tabular}

aThymocytes were isolated from c-FLIP-transgenic mice and their normal FVB strain littermate control (NLC), and the total number of cells determined by hemacytometer. 'FLIP-high' represent pair of mice with relatively high c-FLIP transgene expression; 'FLIP-low' represent pair of mice with relatively low c-FLIP transgene expression. Fractions of thymocyte subpopulations were quantitated by FACS analysis. 


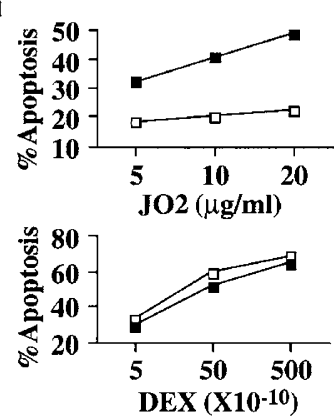

C

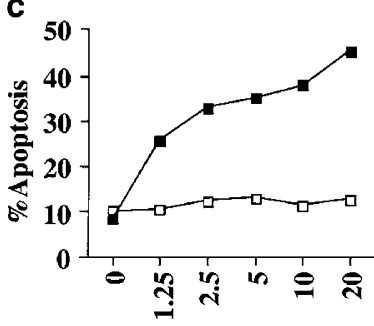

$\operatorname{CD3}(\mu \mathrm{g} / \mathrm{ml})$ b

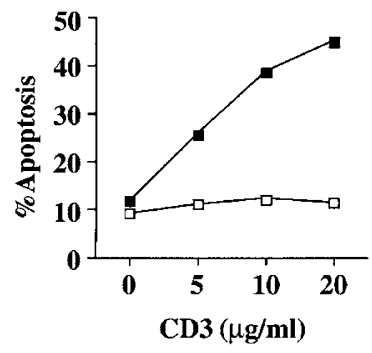

d

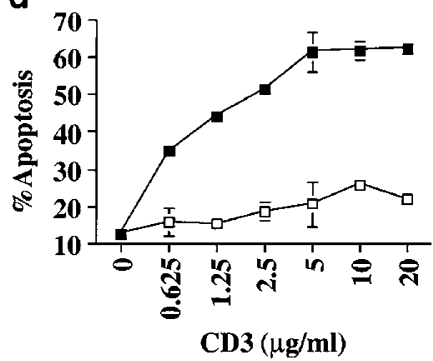

Figure 2 Fas-mediated apoptosis and in vitro AICD suppressed in C-FLIPtransgenic T cells. (a) c-FLIP-transgenic thymocytes were resistant to apoptosis induced by Fas, but not dexamethasone. Thymocytes from NLC (solid square) and c-FLIP-transgenic mice (open square) were treated with Jo2 antibody or dexamethasone at the concentrations indicated. The extent of apoptosis was determined $24 \mathrm{~h}$ later by PI staining, followed by analysis on FACS using the CELLFIT program. (b) c-FLIP transgene prevented in vitro AICD of thymocytes. Thymocytes from NLC and c-FLIP-transgenic mice were stimulated with immobilized anti-CD3 at the indicated concentrations for $30 \mathrm{~h}$, and the fraction of apoptotic cells quantitated. (c, d) In vitro AICD of peripheral T cells suppressed by c-FLIP transgene. (c) Splenic $T$ cells and (d) lymph node $T$ cells were activated by anti-CD3/anti-CD28 for 1 day, followed by IL-2 $(10 \mathrm{U} / \mathrm{ml})$ incubation for an additional 4 days. Viable $T$ cells were then isolated and stimulated with plate-bound anti-CD3 for $20 \mathrm{~h}$, and the fraction of the apoptotic cells was determined

FLIP-transgenic thymocytes were resistant to AICD (Figure 2b). We also examined the sensitivity to AICD in mature T cells. Splenic T cells and lymph node T cells were activated with anti-CD3/anti-CD28, followed by IL-2 incubation for 4 additional days. Preactivated splenic T cells from NLC mice were more sensitive to death induced by low concentrations of anti-CD3 than thymocytes (Figure 2c). Transgenic expression of c-FLIP completely suppressed antiCD3-induced death in preactivated splenic T cells. An equally effective inhibition of AICD was found in lymph node T cells from c-FLIP-transgenic mice (Figure 2d). Inhibition of in vitro activation-induced apoptosis was found in all the c-FLIPtransgenic mice lines that we analyzed.

In contrast to suppression of Fas-mediated apoptosis in cFLIP-transgenic thymocytes, in vitro thymocyte death by neglect was elevated in C-FLIP-transgenic thymocytes. Progressive cell death observed upon in vitro culture of thymocytes was similar between NLC and c-FLIP-transgenic thymocytes during the first day of incubation (Figure 4a), as observed also for the background death of thymocyte AICD (Figure 2b). There was an increased apoptosis for c-FLIPtransgenic thymocytes compared to NLC thymocyte after 2 days of incubation. The elevation in C-FLIP-transgenic thymocyte death was moderate, with an increase of $10-15 \%$

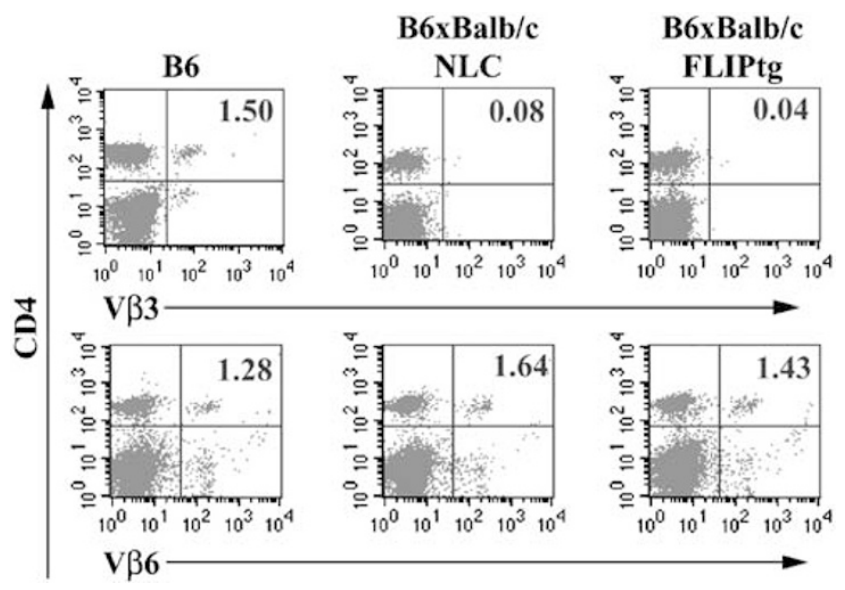

Figure 3 Deletion of $\mathrm{V} \beta 3$ by $m t v 6$ in $\mathrm{BALB} / \mathrm{c}$ mice not prevented by the $\mathrm{c}$-FLIP transgene. $c$-FLIP-transgenic mice of C57BL/6 strain were crossed to BALB/c mice. Splenocytes from C57BL/6 mice, F1 without the c-FLIP transgene, and F1 with the c-FLIP transgene were isolated, and stained for the expression of CD4, $\mathrm{V} \beta 3$, and $\mathrm{V} \beta 6$. The percentage of the $\mathrm{V} \beta 3$ and $\mathrm{V} \beta 6$ populations in $\mathrm{CD} 4^{+}$cells is indicated

over NLC thymocytes 4 days after in vitro incubation (Figure 4a). To determine the effect of c-FLIP expression on thymocyte death in vivo, thymocytes were isolated from NLC and c-FLIP-transgenic mice and the frequency of apoptosis was immediately quantitated. Such measurement underestimated the actual apoptosis, as apoptotic cells are rapidly engulfed, yet a clear difference in apoptosis was observed between normal and c-FLIP-transgenic thymocytes. The frequency of apoptotic cells in normal thymocytes was $1.5 \%$, which was increased to $3.4 \%$ in thymocytes from c-FLIPtransgenic mice (Figure 4b). Elevation of apoptosis in vivo was similar in $\mathrm{CD} 4^{-} \mathrm{CD}^{-}, \mathrm{CD}^{+}{ }^{+} \mathrm{CD} 8^{+}, \mathrm{CD}^{+}{ }^{+} \mathrm{CD} 8^{-}$, and $\mathrm{CD}^{-} \mathrm{CD}^{+}$thymocytes from C-FLIP-transgenic mice (Figure $4 \mathrm{c}$ ), suggesting that the increase in cell death was independent of the maturation stage of thymocytes.

\section{Suppression of proliferation and IL-2 expression with c-FLIP-transgenic $\mathbf{T}$ cells}

We then determined whether the c-FLIP expression could lead to the proliferation defects seen with FADD-deficient, DN-FADD, or caspase-8-deficient T cells. ${ }^{13-25}$ Activationinduced thymocyte proliferation was reduced in c-FLIPtransgenic mice, when activated with anti-CD3/anti-CD28, Con A, or TPA/A23187 (Figure 5a, not shown for Con A and TPA/A23187). Proliferation of splenic T cells triggered with higher concentration of anti-CD3 $(>0.1 \mu \mathrm{g} / \mathrm{ml})$ was suppressed in c-FLIP-transgenic $T$ cells when compared with NLC $T$ cells (Figure $5 b$ ). The possibility that the c-FLIP transgene increases $\mathrm{T}$-cell proliferation when stimulated with low concentrations of antigen ${ }^{27}$ was then examined. Splenic T-cell proliferation, stimulated with low concentrations of antiCD3 (down to $0.01 \mu \mathrm{g} / \mathrm{ml}$ ) for 5 days, was also suppressed in c-FLIP-transgenic T cells (Figure 5c). The inhibition of T-cell proliferation was found in all C-FLIP-transgenic mice, regardless of the c-FLIP expression level. There was no increase in proliferation detected in C-FLIP-transgenic T cells. 

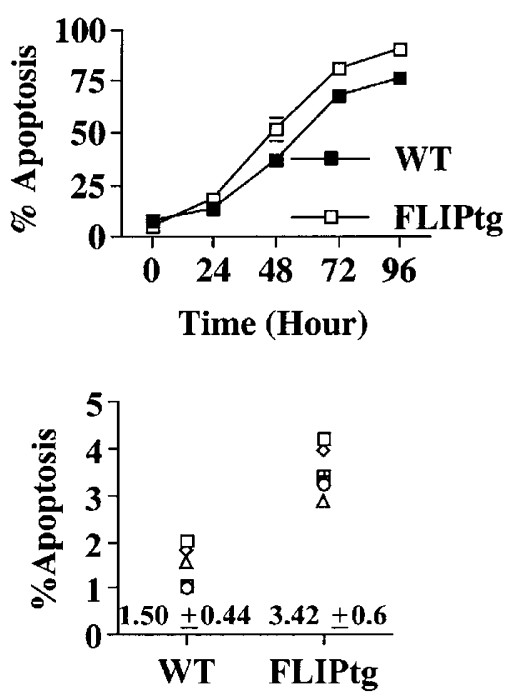

C

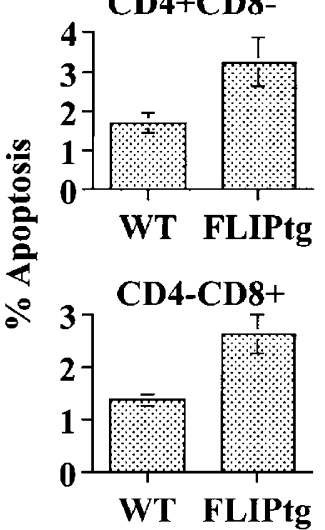

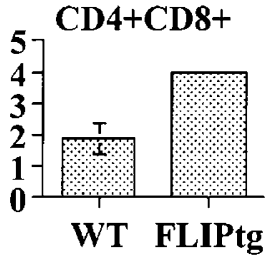

CD4-CD8-

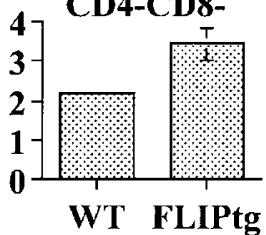

Figure 4 Increased apoptosis of c-FLIP-transgenic thymocytes. (a) Increased in vitro thymocyte death by neglect from c-FLIP-transgenic mice. Thymocytes from four NLC mice and high-c-FLIP-expressing transgenic mice were cultured in vitro in complete RPMI medium. The extent of cell death was determined at 24 , 48,72 , and $96 \mathrm{~h}$, by quantitation of sub-G1 DNA content. (b) Increased apoptosis in thymocytes from c-FLIP-transgenic mice. Thymocytes from five pairs of NLC and C-FLIP-transgenic mice were isolated and immediately analyzed for the frequency of apoptotic cells using Annexin-V staining. The same symbols are used for the same pair of transgenic mouse and its normal littermate. The numbers indicate the average percentage of apoptosis and the standard deviation. (c) Elevated apoptosis in all subpopulation of c-FLIP-transgenic thymocytes. Freshly isolated thymocytes were gated for $\mathrm{CD}^{-} \mathrm{CD}^{-}$, $\mathrm{CD} 4^{+} \mathrm{CD} 8^{+}, \mathrm{CD}^{+}{ }^{\mathrm{CD}} 8^{-}$, and $\mathrm{CD} 4^{-} \mathrm{CD}^{+}$subpopulations, and the fraction of apoptotic cells in each thymocyte subpopulation was determined as in (b)

IL-2 production, another major T-cell activation indicator, was analyzed in C-FLIP-transgenic T cells stimulated by antCD3. IL-2 production from FLIP-transgenic thymocytes was consistently lower than NLC thymocytes (Figure 5d). Therefore, ectopic c-FLIP expression led to reduced T-cell proliferation and decreased IL-2 expression. Inhibition of Tcell activation was more profound in transgenic $T$ cells with high levels of c-FLIP than T cells with lower contents of the cFLIP transgene (FLIP-hi and FLIP-lo in Figure 5e). In addition, suppression of T-cell proliferation by the c-FLIP transgene was found in $\mathrm{CD}^{+}{ }^{+}$as well as $\mathrm{CD} 8^{+}$splenic T cells (data not shown).
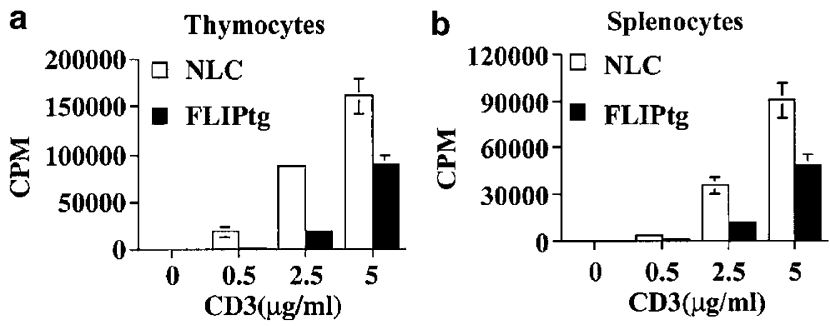

C

d
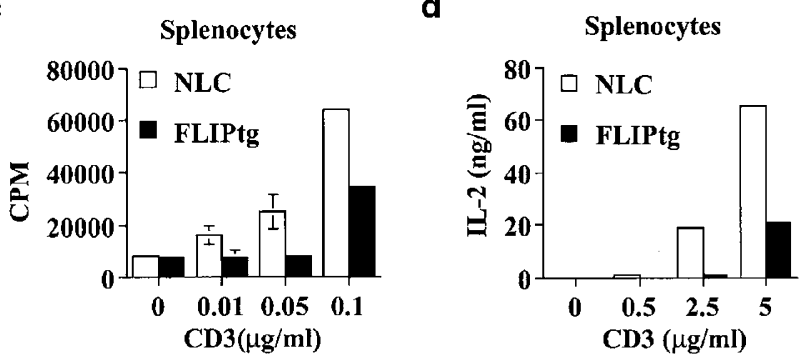

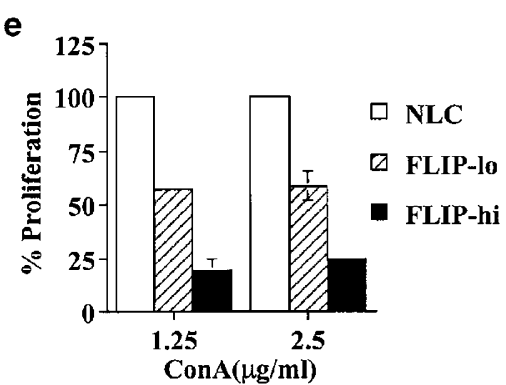

Figure 5 Suppressed proliferation and diminished IL-2 production in C-FLIPtransgenic T cells. (a,b) Proliferation of FLIP-transgenic thymocytes and splenic $T$ cells diminished. (a) Thymocytes and (b) splenic T cells from NLC and c-FLIPtransgenic mice were activated with different concentrations of immobilized anti$\mathrm{CD} 3$, and the incorporation of thymidine was determined $60 \mathrm{~h}$ later. (c) Proliferation of splenic T cells with low concentrations of anti-CD3 stimulant inhibited by the c-FLIP transgene. Splenic T cells from NLC and c-FLIP. transgenic mice were activated with low concentrations of plate-bound anti-CD3, and thymidine incorporation was quantitated $120 \mathrm{~h}$ later. (d) IL-2 production in CFLIP-transgenic T cells compromised. Splenocytes were stimulated with antiCD3 at the indicated concentration and the IL-2 produced was quantitated $24 \mathrm{~h}$ later using the IL-2-dependent cell line HT-2. (e) T-cell proliferation inhibited to a greater extent in transgenic T cells with higher c-FLIP expression. Splenic T cells from c-FLIP-high and c-FLIP-low transgenic mice were stimulated with Con A. The proliferation of c-FLIP-transgenic T cells is compared as a percentage of the NLC T-cell proliferation. The average proliferation of NLC T cells was $61000 \mathrm{cpm}$ for $2.5 \mu \mathrm{g} / \mathrm{ml}$ Con A, and $44000 \mathrm{cpm}$ for $1.25 \mu \mathrm{g} / \mathrm{ml}$ Con A activation

\section{Reduced activation of ERK, p38 MAPK, and NF- $\kappa$ B in c-FLIP-transgenic $T$ cells}

The decrease in T-cell proliferation and IL-2 production suggested a defect in T-cell activation signaling. Some key activation molecules, including ERK, NF- $\kappa \mathrm{B}$, and p38 MAPK, were examined before and after stimulation of c-FLIPtransgenic splenic $T$ cells with TPA/A23187 or anti-CD3/ anti-CD28. ERK activation, detected by a phospho-ERKspecific antibody, was significantly reduced in FLIP-transgenic thymocytes activated through TPA/A23187 (Figure 6a) or CD3/CD28 (Figure $6 b$ ). NF- $\kappa$ B activation was monitored by 


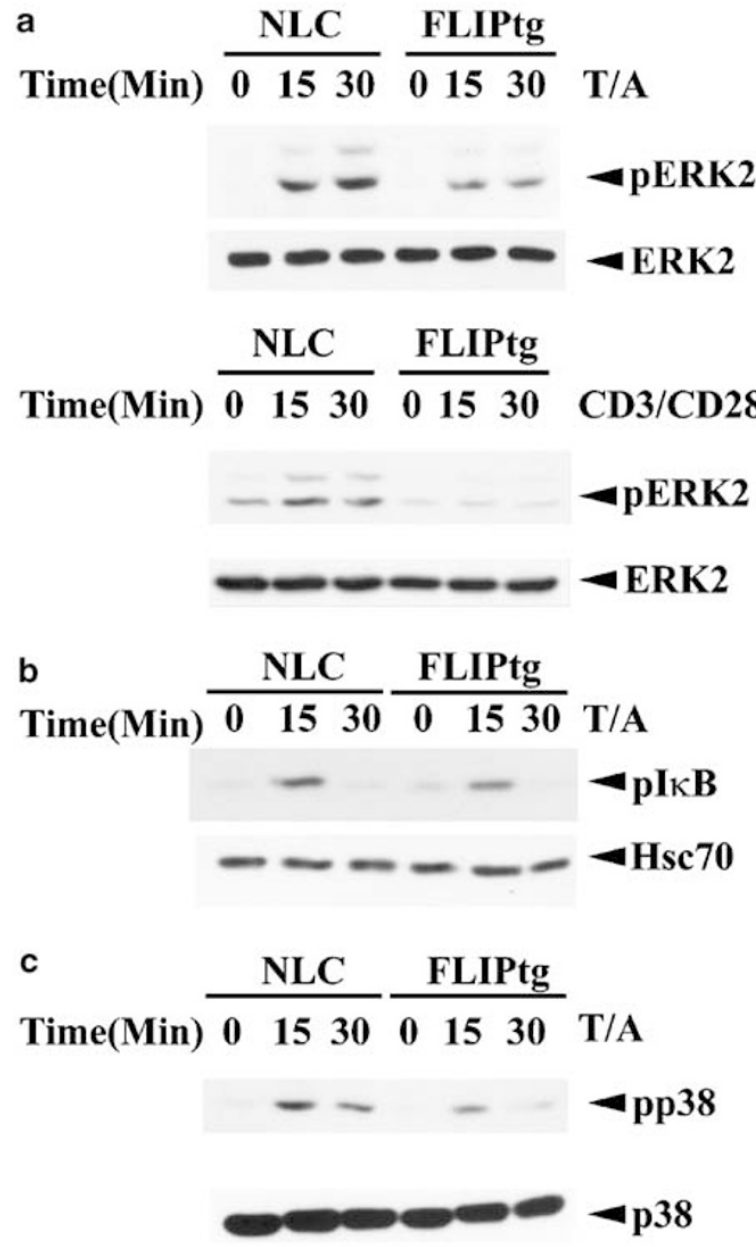

Figure 6 Activation of ERK, NF- $\kappa$ B, and p38 MAPK reduced in c-FLIPtransgenic $T$ cells. Purified splenic $T$ cells from NLC and c-FLIP-transgenic mice were activated with TPA $(10 \mathrm{ng} / \mathrm{ml})$ plus A23187 $(80 \mathrm{ng} / \mathrm{ml})(\mathbf{a}, \mathbf{c}, \mathbf{d})$ or with immobilized anti-CD3 $(10 \mu \mathrm{g} / \mathrm{ml})$ plus anti-CD28 $(5 \mu \mathrm{g} / \mathrm{ml})(\mathbf{b})$ for the indicated times, and cell extracts were prepared. $(\mathbf{a}, \mathbf{b})$ The phospho-ERK levels were determined by immunoblots using anti-phosphorylated T202/Y204 ERK antibody. ERK2 was quantitated by anti-ERK2 antibody C-14. (c) The extent of $\mathrm{I}_{\kappa} \mathrm{B}$ phosphorylation was assessed by immunoblots using phospho- $\mathrm{I}_{\kappa} \mathrm{B}$ antibody. (d) The extent of T-cell activation was measured by immunoblots using anti-p38 $\alpha$ antibody C-20 and anti-phosphorylated (T180/Y182) p38 MAPK antibody

$I_{\kappa} \mathrm{B}$ phosphorylation. No $\left.\right|_{\kappa} \mathrm{B}$ phosphorylation was detected in $T$ cells with or without C-FLIP $\mathrm{P}_{\mathrm{L}}$ before stimulation (Figure $6 \mathrm{~b}$ ). The extent of $\mathrm{I} \kappa \mathrm{B}$ phosphorylation was reduced in $\mathrm{C}-\mathrm{FLIP}_{\mathrm{L}}-$ transgenic $\mathrm{T}$ cells activated with TPA/A23187. NF- $\kappa \mathrm{B}$, like ERK, was suppressed in C-FLIP-transgenic $T$ cells upon activation. In addition, a reduction in p38 MAPK activation, essential for T-cell proliferation and IL-2 expression, was observed in $\mathrm{T}$ cells with transgenic $\mathrm{c}-\mathrm{FLIP}_{\mathrm{L}}$ (Figure $6 \mathrm{c}$ ). The suppression of T-cell activation in C-FLIP transgenic $T$ cells correlated with the attenuated activation of $\mathrm{ERK}, \mathrm{NF}-\kappa \mathrm{B}$, and p38 MAPK.

FADD-deficient $T$ cells also display aberrant cell cycling. ${ }^{18}$ We studied whether c-FLIP overexpression led to a defective regulation of the cell cycle in $T$ cells. There was a small fraction of $c$-FLIP-transgenic splenic $T$ cells in $S$ and G2/M phases before TCR stimulation (Figure 7a).
After stimulation with anti-CD3/anti-CD28, higher cell cycling was found with NLC T cells than with c-FLIP-transgenic $\mathrm{T}$ cells. Consistent with the decreased TCR-stimulated proliferation in C-FLIP-transgenic $\mathrm{T}$ cells (Figure 5), there was small reduction in the expression of cyclin E, cyclin D2, cdk2, and cdk4 after CD3/CD28 activation (Figure 7b). The induction of CDK inhibitor p21 was moderately enhanced in c-FLIP-transgenic $\mathrm{T}$ cells, relative to normal $\mathrm{T}$ cells, stimulated with CD3/CD28. Therefore, c-FLIP-transgenic T cells are reminiscent to FADD-deficient $T$ cells in the spontaneous cell cycling, increased TCR-triggered p21 expression, and decreased TCR-induced cyclin D2 expression. In contrast, the elevated expression of cyclin E and cdk2, characteristic for resting FADD-deficient $T$ cells, ${ }^{18}$ was not found in c-FLIP-transgenic T cells (Figure 7), indicating the distinction in cell cycle between FADD-/- T cells and c-FLIPtransgenic $\mathrm{T}$ cells

\section{High levels of c-FLIP expression interferes with thymocyte development}

Although inhibition of Fas-mediated AICD and suppression of T-cell activation were found in all c-FLIP-transgenic mice, the extent of inhibition was more profound in mice with elevated cFLIP expression (Figure 5e). Thymocyte profiles in transgenic mice also correlated with their c-FLIP expression levels. FACS analysis of CD4 and CD8 expression on thymocytes from high-expressing C-FLIP-transgenic mice revealed disturbed thymocyte CD4/CD8 profiles. In high-expressing cFLIP-transgenic mice of $\mathrm{C} 57 \mathrm{BL} / 6$ strain, there was a moderate decrease in $\mathrm{CD}^{+}{ }^{+} \mathrm{CD}^{-}$(8.3 to $\left.5.8 \%\right)$ and $\mathrm{CD}^{-}$ $\mathrm{CD}^{+}(2.2$ to $1.9 \%)$ populations, together with a proportional increase of $\mathrm{CD}^{+}{ }^{+} \mathrm{CD} 8{ }^{+}$thymocytes when compared to NLC mice (Figure 8a, B6). The disturbance for thymocyte development by c-FLIP was more evident on FVB mice than on C57BL/6 mice, due to the presence of higher proportions of single positive thymocytes in FVB mice. The $\mathrm{CD} 4{ }^{+} \mathrm{CD} 8^{-}$ thymocytes were reduced from 16.2 to $11.2 \%$, and the $\mathrm{CD}^{-} \mathrm{CD}^{+}{ }^{+}$thymocytes were decreased from 4.2 to $2.6 \%$ in transgenic mice with elevated c-FLIP transgene expression (Figure 8a, FVB-hi). The disturbance of thymocyte development was more conspicuous when the absolute cell numbers of individual thymic subpopulation from six pairs of FVB mice were compared (Table 1). In transgenic mice with high c-FLIP expression, $\mathrm{CD}^{-} \mathrm{CD}^{+}$thymocytes were decreased from $3.6 \times 10^{6}$ to $1.8 \times 10^{6}$ cells and $\mathrm{CD}^{+}{ }^{+} \mathrm{CD}^{-}$thymocytes reduced from $15.4 \times 10^{6}$ to $5.9 \times 10^{6}$ cells. In contrast, the thymocyte profile (Figure $8 \mathrm{a}, \mathrm{FVB}-\mathrm{lo}$ ) of transgenic mice with low c-FLIP expression levels was almost indistinguishable from those of NLC mice. Fractions of the peripheral mature T cells were also reduced in transgenic mice with high c-FLIP expression (Figure $8 \mathrm{~b}$ ), likely to have resulted from impaired development of $\mathrm{CD}^{+}{ }^{+} \mathrm{CD} 8^{-}$and $\mathrm{CD} 4^{-} \mathrm{CD} 8^{+}$thymocytes. The percentage of splenic CD4 ${ }^{+}$T cells in c-FLIP-transgenic mice was reduced from 34 to $24 \%$ in FVB mice, concurrent with $\mathrm{CD}^{+}{ }^{+}$T cells decreasing from 10 to $7 \%$ (Figure 8b, FVBhi). In contrast, a smaller disturbance in splenic T-cell development was found in transgenic lines with lower levels of c-FLIP expression (Figure 8b, FVB-lo). Therefore, perturbation of T-cell development was more prominent in mice with 
a

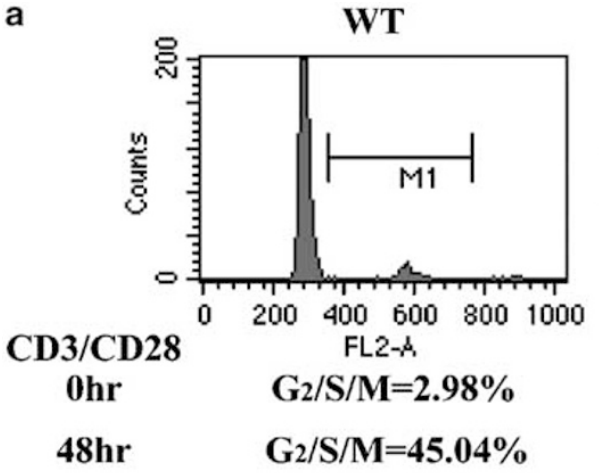

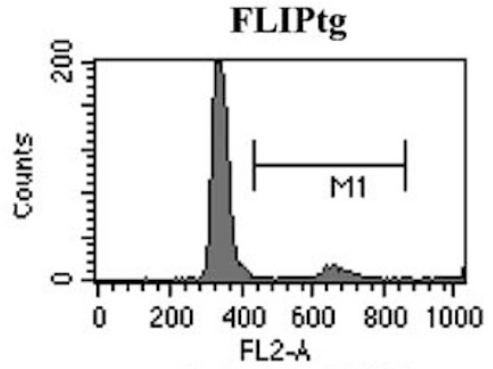

$\mathbf{G} 2 / \mathbf{S} / \mathbf{M}=6.23 \%$

$\mathrm{G} 2 / \mathrm{S} / \mathrm{M}=36.62 \%$

b

\begin{tabular}{ccc} 
WT & FLIPtg & \\
\cline { 1 - 2 }+- & CD3/CD28 \\
- & Cyclin E \\
$-\quad-$ & Cyclin D2 \\
- & Cdk4 \\
- & Cdk2 \\
$--\infty$ & p21
\end{tabular}

Figure 7 Cell cycle abnormality in c-FLIP-transgenic T cells. (a) Residual cell cycling in c-FLIP-transgenic T cells. Purified splenic T cells from c-FLIP-transgenic and NLC mice were stimulated with anti-CD3/anti-CD28 for $48 \mathrm{~h}$, and the fraction of T cells in S and G2/M phages were quantitated before and after activation. (b) Analysis of cell cycle protein. Purified splenic T cells were stimulated with anti-CD3/anti-CD28 for $24 \mathrm{~h}$ and the contents of cyclin D2, cyclin E, cdk2, cdk4, and p21 before and after activation were determined by immunoblots

high levels of the c-FLIP transgene than mice with low c-FLIP expression.

We further elucidated whether a reduction in mature thymocytes might be attributed to attenuated T-cell activation in mice with high level of c-FLIP transgene. Thymocyte positive selection is correlated with increased expression of CD69. The frequency of $\mathrm{CD}^{2} 9^{+}$thymocytes was lower in cFLIP-transgenic mice than in NLC mice (Figure 9a). Among $\mathrm{CD} 4{ }^{+} \mathrm{CD}^{-}$and $\mathrm{CD} 4{ }^{-} \mathrm{CD} 8^{+}$thymocytes, the fractions of $\mathrm{CD} 9^{+}$populations were reduced in C-FLIP-transgenic mice compared to normal mice. The development of $\mathrm{CD} 4^{+} \mathrm{CD} 8^{-}$ thymocytes into mature thymocytes was also marked by upregulation of CD5, class I MHC, and TCR. There was a clear reduction in the fraction of $\mathrm{CD}^{+}$, class $1 \mathrm{MHC}^{+}$, and $\mathrm{TCR}^{+}$in $\mathrm{CD}^{+}{ }^{+} \mathrm{CD}^{-}$and $\mathrm{CD} 4^{-} \mathrm{CD}^{+}{ }^{+}$thymocytes from cFLIP-transgenic mice, even though the mean intensity of CD5 and CD69 was not significantly altered (Figure 9b). There was a moderate decrease in the TCR level in C-FLIP-transgenic mice. Therefore, the decrease in mature $T$ lymphocytes in C-FLIP-transgenic mice was partly linked to reduced TCRmediated selection.

\section{Discussion}

FADD and caspase-8 are known to be essential for T-cell activation; however, the activation signals transmitted by
FADD and caspase-8 are poorly understood. ${ }^{25}$ In this study, we produced transgenic mice with T-cell-specific expression of c-FLIP, the specific inhibitor of FADD and caspase-8, to examine how T-cell activation would be affected. Despite the variation in c-FLIP transgene expression, Fas-mediated apoptosis and in vitro AICD were suppressed in all transgenic $T$ cells (Figure 2). Therefore, even low levels of c-FLIP transgene conferred resistance of $T$ lymphocytes to Fasinduced cell death. In addition, we observed suppressed proliferation of $\mathrm{T}$ cells in all transgenic mice (Figure 5). Defective proliferation is found in T cells from FADD-deficient chimeric mice and dominant-negative FADD-transgenic mice ${ }^{13-20}$ and in $T$ cells with inactivated caspase- $8 .{ }^{21-25}$ Overexpression of c-FLIP, therefore, results in T-cell proliferation defects similar to those with FADD and caspase-8 inactivation. FADD-/- T cells are also characteristic for cycling before TCR ligation and for the enhanced p21 induction the suppressed cyclin D2 expression after TCR stimulation. ${ }^{18}$ The spontaneous T-cell cycling, increased p21 induction, and reduced cyclin D2 expression were also detectable in C-FLIP-transgenic mice (Figure 7). We propose that part of the activation defect observed in C-FLIPtransgenic $T$ cells is due to neutralization of FADD or caspase- 8 by c-FLIP.

C-FLIP-transgenic $T$ cells also exhibited signaling defects not found in FADD-/- or caspase-8-deficient $T$ cells. 
a

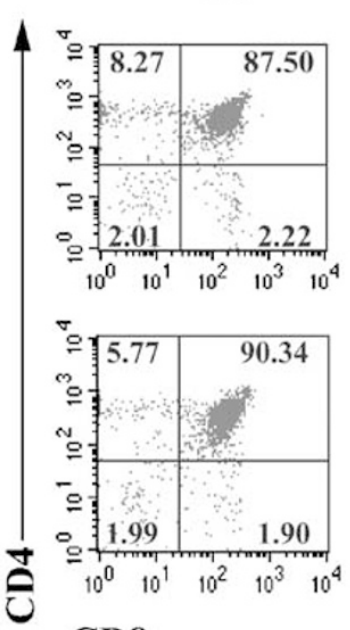

CD8
FVB-hi
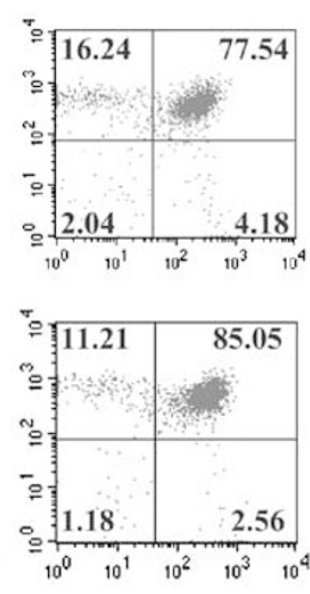

FVB-Io
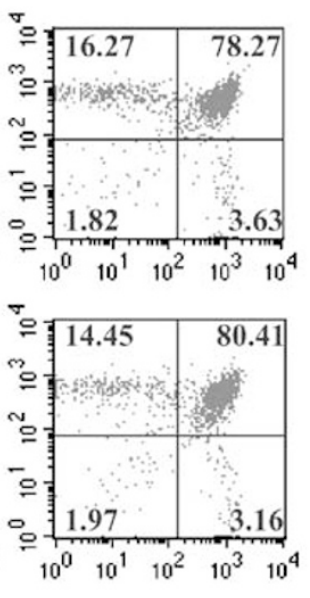

NLC

\section{FLIPtg}

b

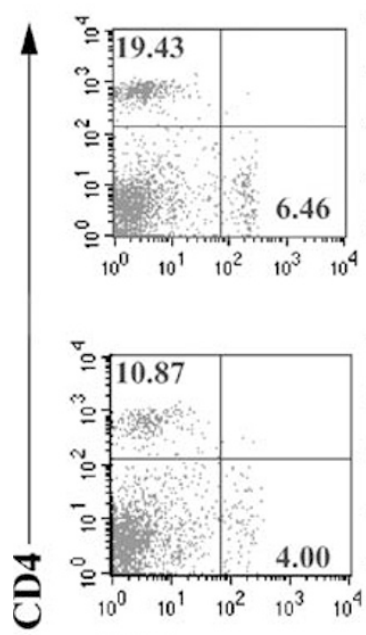

FVB-hi
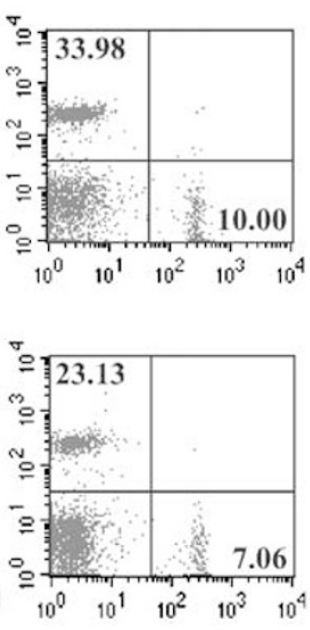

\section{CD8}

Figure 8 Impaired T-cell development in transgenic mice with high c-FLIP expression. FACS profiles of thymocytes (a) and splenocytes (b) from 6-week-old NLC and c-FLIP-transgenic mice stained for CD4 and CD8, using PE-conjugated anti-CD4 and FITC-conjugated anti-CD8 antibodies. Profiles from three pairs of transgenic mice are displayed: c-FLIP-high of C57BL/6 (B6), c-FLIP-high of FVB (FVB-hi), and c-FLIP-low of FVB (FVB-lo). The numbers indicate the percentage of thymocyte subpopulation or the fraction of $\mathrm{CD}^{+}$and $\mathrm{CD}^{+}$splenocytes

Reduced IL-2 expression was found in C-FLIP-transgenic mice (Figure 5), but not in FADD-/- or DN-FADD T cells. ${ }^{15,17,19}$ In addition, in our studies, ERK, p38 MAPK, $\mathrm{NF}-\kappa \mathrm{B}$ activation was attenuated in c-FLIP-transgenic T cells (Figure 6), yet is normal in DN-FADD T cells and caspase-8deficient T cells. ${ }^{17,19,24}$ There were also effects that were not easily assigned to either FADD or caspase-8. For example, resting FADD-1- T cells exhibit a constitutive expression of cyclin $E$ and cdk2, ${ }^{18}$ yet the levels of cyclin $E$ and cdk2 were nearly normal in c-FLIP-transgenic T cells (Figure 7b). Overall, the suppression of T-cell activation seen in C-FLIP. transgenic mice cannot be fully accounted for by inhibition of FADD or caspase-8. Interestingly, inhibition of IL-2 production, seen in C-FLIP-transgenic T cells (Figure 5), has also been observed in T cells treated with caspase-8 inhibitors, ${ }^{21} \mathrm{~T}$ cells from patients with defective caspase $-8,{ }^{23}$ and $T$ cells from caspase-8-deficient mice. ${ }^{24}$ Whether the defective IL-2 expression in c-FLIP-transgenic T cells could be attributed to an inactivated caspase-8 deserves further investigation.

We also observed that high level of c-FLIP expression disturbed T-cell development (Figure 8 and Table 1). Reduction was prominent in $\mathrm{CD} 4^{+} \mathrm{CD} 8^{-}$and $\mathrm{CD} 4^{-} \mathrm{CD} 8^{+}$thymocyte subpopulations, both in their frequencies (Figure $8 \mathrm{a}$ ) and in absolute cell numbers (Table 1) for mice expressing high levels of the c-FLIP transgene. A similar decrease in $\mathrm{CD}^{+}{ }^{+} \mathrm{CD} 8^{-}$and $\mathrm{CD}^{-}{ }^{-} \mathrm{CD} 8^{+}$thymocytes was found previously in c-FLIP-transgenic mice (Figure 4 in Lens et al. ${ }^{27}$ ). In contrast, interference with thymocyte development was not 
a

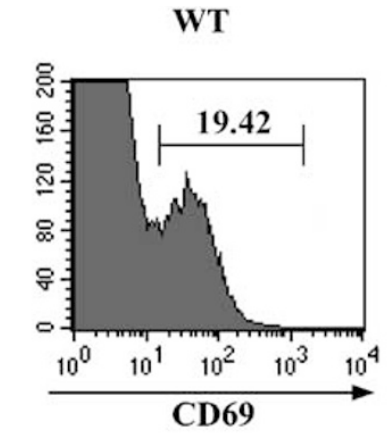

b

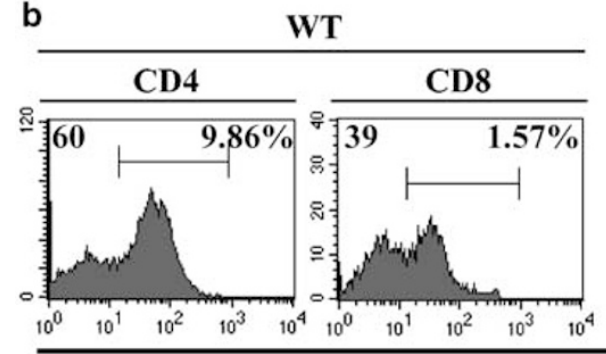

FLIPtg

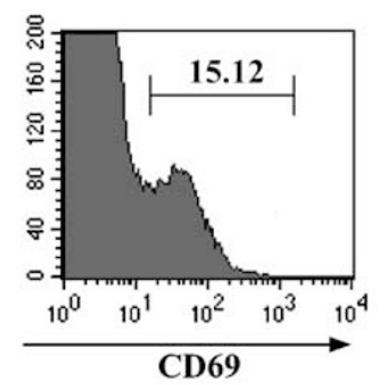

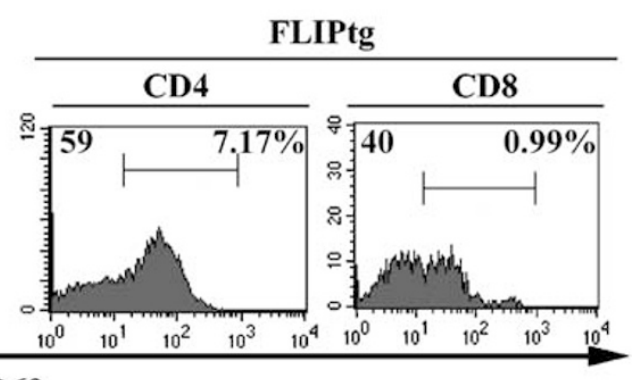

CD69
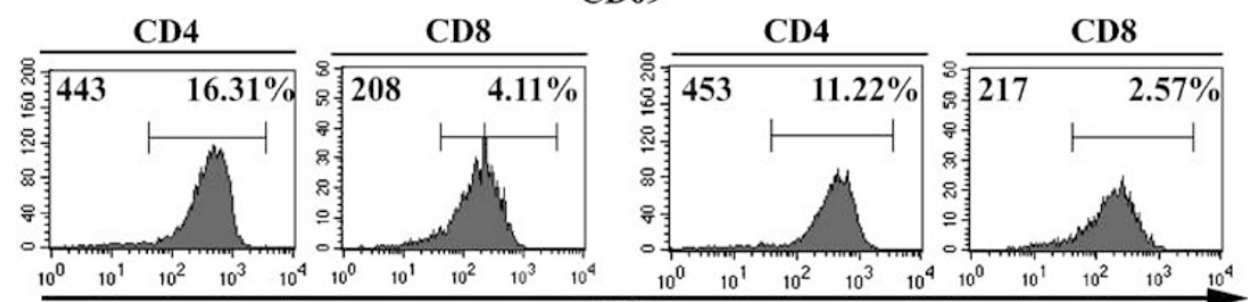

CD5
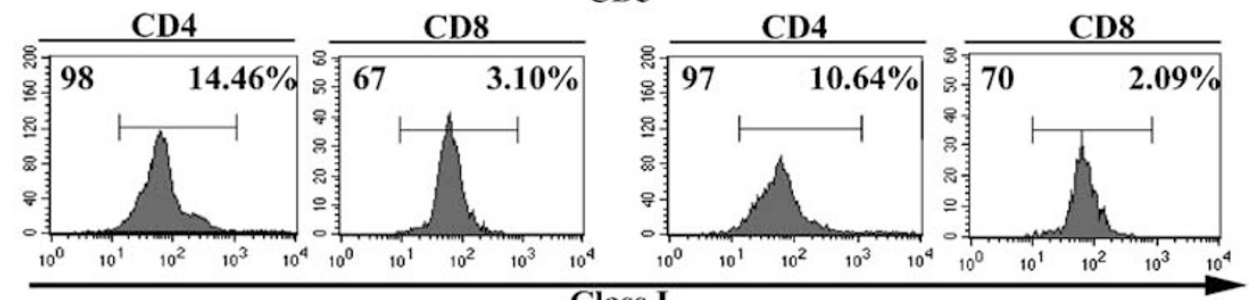

Class I
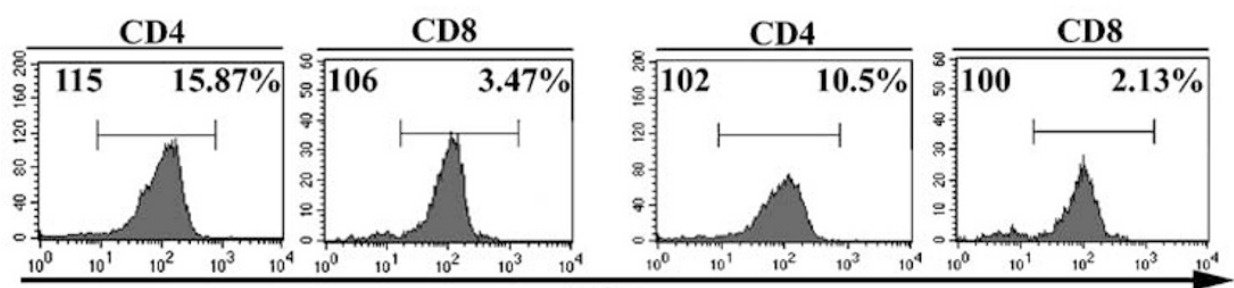

\section{TCR}

Figure 9 Reduced positive selection of thymocytes in mouse with high c-FLIP expression. (a) CD69 expression in thymocytes from NLC mice and c-FLIP-hi-transgenic mice. The percentages of $\mathrm{CD} 69^{+}$thymocytes are indicated. (b) Expression of maturation markers on CD4 ${ }^{+} \mathrm{CD} 8^{-}$and $\mathrm{CD} 4^{-} \mathrm{CD} 8^{+}$thymocytes in NLC and c-FLIPtransgenic mice. $\mathrm{CD} 4^{+} \mathrm{CD} 8^{-}$and $\mathrm{CD} 4^{-} \mathrm{CD} 8^{+}$thymocytes were gated and analyzed for the expression of $\mathrm{CD} 69, \mathrm{CD} 5, \mathrm{MHC}$ class I ( $\left.\mathrm{D}^{q}\right)$, and TCR $\alpha \beta$. Numbers above the peak are the percentage of thymocytes in the gated range. Numbers in the upper left end are the mean fluorescence intensity of the thymocytes in the same gate

apparent in T cells with low expression of transgenic c-FLIP (Table 1 and Figure 8), despite Fas-mediated apoptosis being effectively suppressed in these T cells. The ability of c-FLIP to antagonize Fas-induced apoptosis, therefore, is dissociated from the effect of c-FLIP on thymocyte development. We speculate that the impaired thymocyte development is likely linked to the suppressed T-cell activation in the presence of cFLIP overexpression. T-cell proliferation was inhibited to a 
greater degree in transgenic $T$ cells with higher expression of c-FLIP (Figure 5e). In addition, there was a significant reduction in mature thymocytes expressing CD69, CD5, class I $\mathrm{MHC}$ and TCR in mice overexpressing C-FLIP (Figure 9). Attenuation of TCR-initiated activation signals in c-FLIPtransgenic thymocytes (Figure 6) may result in reduced TCRmediated selection of the $\mathrm{CD} 4{ }^{+} \mathrm{CD} 8{ }^{+}$thymocytes, leading to a decrease in mature thymocytes and peripheral $\mathrm{T}$ cells (Figure 8).

Similar to the disturbance of thymocyte development, a decrease in thymocyte number also correlated with expression levels of c-FLIP (Table 1). That transgenic expression of c-FLIP and v-FLIP leads to a reduction in thymocyte numbers has also been previously documented. ${ }^{27,34}$ At least two different mechanisms may be proposed for the reduction in thymocyte number as a consequence of elevated c-FLIP expression. First, elevated c-FLIP suppresses T-cell activation to a greater extent (Figure $5 e$ ), resulting in diminished survival signals and decreased thymocyte survival. Second, c-FLIP has been shown to exhibit proapoptotic effect. $^{4,6,8,9,37,38}$ Consistent with these reports, we found an increase in the death of thymocytes from transgenic mice with c-FLIP overexpression (Figure 4), likely contributing to the reduction in total thymocyte number in c-FLIP-transgenic mice. It may be noted that apoptosis induced by c-FLIP overexpression was independent of the developmental stage of thymocytes; increased cell death was found in immature as well as in mature thymocyte populations (Figure 4), which may explain why the number of $\mathrm{CD}^{-}{ }^{-} \mathrm{CD} 8^{-}$thymocyte was also reduced in C-FLIP-transgenic mice (Table 1).

The in vivo activation-induced death of $\mathrm{T}$ cells, including thymocyte negative selection, is known to be Bim-dependent but Fas-independent. ${ }^{35,36}$ Therefore, overexpression of c-FLIP was not expected to interfere with in vivo AICD, as observed in this and previous C-FLIP-transgenic studies. ${ }^{27}$ In the present study, c-FLIP effectively suppressed the in vitro AICD in all transgenic $T$ cells we generated (Figure 2). Fas-FasL interaction plays a dominant role in the in vitro activation-induced T-cell death. ${ }^{1,30-33}$ c-FLIP expression, which blocks T-cell activation, may prevent in vitro activation-induced T-cell death through inhibition of activationinduced FasL expression and Fas upregulation.

The effect of c-FLIP overexpression on T-cell development (Figures 8 and 9) is distinct from the inactivation of FADD or caspase-8, suggesting that some of the c-FLIP biological activities are not mediated by neutralization of FADD and caspase-8 alone. The exact mechanisms on how c-FLIP suppresses T-cell activation and T-cell development deserve further characterization. In contrast, c-FLIP was recently reported to promote $\mathrm{T}$-cell activation and lead to increased $\mathrm{T}$ cell proliferation and IL-2 production. ${ }^{27,28}$ We did not detect these stimulatory effects of c-FLIP in the nine transgenic lines we produced. Instead, increased suppression of T-cell proliferation correlates with an elevated expression of the cFLIP transgene (Figure 5e), suggesting an inhibitory nature of c-FLIP overexpression on T-cell activation. Since the reported enhanced proliferation was observed only when c-FLIP. transgenic $T$ cells were stimulated by low concentrations of anti-CD3 or antigen, ${ }^{27}$ minimum activating concentrations of anti-CD3 and Con A were thus used to stimulate c-FLIP. transgenic splenic T cells. However, suppression of T-cell proliferation was consistently observed with c-FLIP-transgenic $T$ cells (Figure $5 \mathrm{c}$ ). In addition, the several $\mathrm{T}$-cell activation signals examined decreased in c-FLIP-transgenic $T$ cells compared to normal T cells (Figure 6). Despite the report that C-FLIP couples to Raf-1 for ERK activation, and binds to TRAF1/TRAF2 for NF- $\kappa$ B activation, ${ }^{22}$ we found no ERK activity or NF- $\kappa \mathrm{B}$ activation in the resting c-FLIP-transgenic $\mathrm{T}$ lymphocytes (Figure 6). In contrast, ERK activity and NF- $\kappa \mathrm{B}$ activation were attenuated in c-FLIP-transgenic $T$ cells (Figure 6). Dissociation of c-FLIP expression from NF- $\kappa \mathrm{B}$ activation has also been supported by recent studies. ${ }^{39,40} \mathrm{NF}$ $\kappa \mathrm{B}$ activation is not reduced in c-FLIP-deficient cells. ${ }^{39} \mathrm{c}-\mathrm{FLIP}$ is unable to activate $I \kappa \mathrm{B}$ kinase complex in primary effusion lymphoma. ${ }^{40}$ All the above-mentioned discrepancies could be due to differences in the expression level of c-FLIP transgene, yet also illustrate that c-FLIP overexpression does not necessarily lead to increased T-cell proliferation and elevated $\mathrm{ERK} / \mathrm{NF}-\kappa \mathrm{B}$ activation.

In summary, expression of c-FLIP, even at a low level, prevented Fas-mediated apoptosis and inhibited T-cell proliferation and IL-2 production. High levels of c-FLIP expression also led to disturbed T-cell development, likely caused by effective suppression of TCR-initiated activated signals. Our results also suggest that c-FLIP expression does not necessarily promote $\mathrm{T}$-cell proliferation and increase T-cell activation. The ability to activate signals is probably not an inherent property associated with c-FLIP. Instead, increased c-FLIP expression results in T-cell inactivation. The inhibitory effect of c-FLIP on T-cell activation could be partly attributed to inactivation of FADD or caspase-8. c-FLIP may thus be a useful tool to elucidate some of the activation signals transmitted by FADD and caspase-8. However, c-FLIP also stimulates signals that are independent of FADD and caspase-8, contributing to events such as enhanced thymocyte death and suppressed thymocyte maturation. The overall phenotype of c-FLIP expression in vivo is likely a summation of physiological effects from both FADD/caspase-8 inactivation and c-FLIP-specific signals.

\section{Materials and Methods}

\section{Reagents and cell lines}

Con A, TPA, and A23187 were purchased from Sigma Chemical Co. (St. Louis, MO, USA). The following antibodies were purchased from Caltag (Burlingame, CA, USA): mouse CD4 (clone CT-CD4, FITC- or TriColorconjugated), CD5.2 (clone CG16, FITC-conjugated), CD8 (clone CTCD8a, PE, or TriColor-conjugated), CD69 (clone H1.2F3, FITCconjugated), and TCR (H57-597, FITC-conjugated). PE-conjugated antiCD4 (GK1.5) and FITC-labeled anti-CD8 (53-6.7) were purchased from eBioscience (San Diego, CA, USA). FITC-conjugated anti-Dq was obtained from BD-PharMingen (San Diego, CA, USA). Splenic $T$ lymphocytes were isolated by panning twice on plates precoated with goat anti-mouse Ig antibody (Sigma) and the purity was confirmed by FACS to be $>92 \%$. For studies on activation-induced apoptosis, splenic $T$ cells were activated with anti-CD3/anti-CD28 for $24 \mathrm{~h}$. Activated splenic T cells were then washed and incubated in the presence of IL-2 $(10 \mathrm{U} / \mathrm{ml})$ for another 4 days before anti-CD3 treatment. 


\section{Plasmids}

Preparation of $\mathrm{C}-\mathrm{FLIP} \mathrm{P}_{\mathrm{L}}$ CDNA was previously described. ${ }^{41}$ p1017 containing the Ick $3.2 \mathrm{~kb}$ proximal promoter and $3^{\prime}$ untranslated region of growth hormone (mini gene exons 1-5) was a gift from Dr. Roger Perlmutter (University of Washington, Seattle). The human CD2 cassette $^{29}$ was a gift from Dr. Dimitris Kioussis (National Institute for Medical Research, London). Transgenic mice were generated in the transgene/knockout core of Institute of Molecular Biology, Academia Sinica (Taipei, Taiwan). p1017-c-FLIP , and CD2-C-FLIP injected into the pronuclei of both C57BL/6 and FVB zygotes. Nine independent founders were obtained. All transgenic mice were maintained in the SPF mice facility of Institute of Molecular Biology, Academia Sinica. All mice experiments were approved by the Experimental Animal Committee, Academia Sinica.

\section{Cell death measurement}

All cultures were performed in RPMI with $10 \%$ fetal calf serum (both from GIBCO, Grand Island, NY, USA), $10 \mathrm{mM}$ glutamine, $100 \mathrm{U} / \mathrm{ml}$ penicillin, $100 \mathrm{mg} / \mathrm{ml}$ streptomycin, and $2 \times 10^{-5} \mathrm{M}$ 2-ME. The extent of apoptosis was determined by propidium iodide (PI) staining. At the end of different treatments, cells were resuspended in hypotonic fluorochrome solution $(50 \mu \mathrm{g} / \mathrm{ml} \mathrm{PI}, 0.1 \%$ sodium citrate, $0.1 \%$ Triton $\mathrm{X}-100),{ }^{42}$ and placed at $4^{\circ} \mathrm{C}$ in the dark overnight. DNA contents were analyzed by FACScan (Becton Dickinson, Mountain View, CA, USA). Fraction of cells with subG1 DNA content was assessed using the CELLFIT software program (Becton Dickinson).

\section{Nuclear extract and total cell extract}

T cells were lysed in $10 \mathrm{mM}$ Tris- $\mathrm{HCl}(\mathrm{pH} 7.4), 10 \mathrm{mM} \mathrm{NaCl}, 3 \mathrm{mM} \mathrm{MgCl}$, and $0.5 \%$ Nonidet P-40 (NP-40). The lysates were incubated on ice for $5 \mathrm{~min}$ and were centrifuged at $1500 \mathrm{rpm}$ for $5 \mathrm{~min}$ at $4^{\circ} \mathrm{C}$. The pellet (nuclei) was suspended in hypertonic buffer containing $20 \mathrm{mM} \mathrm{HEPES}(\mathrm{pH}$ 7.9), $1.5 \mathrm{mM} \mathrm{MgCl}_{2}, 0.3 \mathrm{M} \mathrm{KCl}, 0.5 \mathrm{mM}$ DTT, $1 \mathrm{mM} \mathrm{PMSF}, 20 \%$ glycerol, and $0.4 \mathrm{mM}$ EDTA, and agitated at $4{ }^{\circ} \mathrm{C}$ for more than $30 \mathrm{~min}$. The mixture was centrifuged at $13000 \mathrm{rpm}$ for $10 \mathrm{~min}$. The supernatant was then mixed with two volumes of the above buffer (without $\mathrm{KCl}$ ) and frozen immediately. Total cell extracts were prepared by resuspending cells in hypotonic buffer containing $10 \mathrm{mM}$ HEPES (pH 7.9), $1.5 \mathrm{mM} \mathrm{MgCl}$, $10 \mathrm{mM} \mathrm{KCl}, 0.5 \mathrm{mM}$ DTT, $0.5 \mathrm{mM}$ PMSF, $100 \mu \mathrm{g} / \mathrm{ml}$ aprotinin, $1.25 \mu \mathrm{g} / \mathrm{ml}$ leupeptin, and lysed by three cycles of freezing and thawing. One-tenth volume of $3 \mathrm{M} \mathrm{KCl}$ was then added, and the lysates agitated at $4{ }^{\circ} \mathrm{C}$ for $30 \mathrm{~min}$. Lysates were obtained following the same procedures as those used for isolation of nuclear extracts. Protein concentrations were determined by Bradford assay (Bio-Rad, Richmond, CA, USA).

\section{Immunoblot}

Cell extracts $(30-50 \mu \mathrm{g})$ were resolved by $10 \%$ SDS-PAGE and transferred to PVDF membranes (Millipore, Bedford, MA, USA) for $4 \mathrm{~h}$ at $20 \mathrm{~V}$. Membranes were washed in rinse buffer (PBS with $2 \%$ Tween 20) at room temperature for $15 \mathrm{~min}$ and incubated in blocking buffer $(5 \%$ nonfat milk in rinse buffer) for $1.5 \mathrm{~h}$. The membrane was then incubated with primary antibody for $2 \mathrm{~h}$ at room temperature and afterwards washed three times with rinse buffer. The membrane was then incubated with $1: 1000$ diluted horseradish peroxidase-conjugated anti-rabbit Ig antibody (Santa Cruz) followed by development with ECL reagents (Amersham, Buckinghamshore, UK). The primary antibodies used were: anti-FLIPS/L
(H-202), anti-ERK2 (C-14), anti-p38 $\alpha$ (C-20) (from Santa Cruz Biotech, Santa Cruz, CA, USA); anti-phospho (T202/Y204) ERK, anti-phospho (T180/Y182) p38 MAPK, anti-phospho I $\kappa$ B (from Cell Signaling, Beverly, MA, USA). All antibodies against cell cycle protein were obtained from Santa Cruz.

\section{Acknowledgements}

We thank Dr. Roger Perlmutter for p1017 vector, Dr. Dimitris Kioussis for the CD2 cassettes, Dr. Leo Wang for transgenic mice construction, and Dr. Ken Deen for editing the manuscript. This work was supported by a grant from Academia Sinica, Grant 90-2320-B001-059 from National Science Council, and Grant NHRI-Ex92-9217BI from National Health Research Institute, Taiwan, ROC.

\section{References}

1. Nagata $S$ (1997) Apoptosis by death factor. Cell 88: $355-365$

2. Wajant $H(2002)$ The Fas signaling pathway: more than a paradigm. Science 296: $1635-1636$

3. Irmler M, Thome M, Hahne M, Schnedier P, Hofmann K, Steiner V, Bodmer JL, Schroter M, Burns K, Mattmann C, Rimoldi D, French LE and Tschopp J (1997) Inhibition of death receptor signals by cellular FLIP. Nature 388: 190-195

4. Goltsev YV, Kovalenko AV, Arnold E, Varfolomeev EE, Brodianskii VM and Wallach D (1997) CASH, a novel caspase homologue with death effector domains. J. Biol. Chem. 272: 19641-19644

5. Hu S, Vincenz C, Ni J, Gentz R and Dixit VM (1997) I-FLICE, a novel inhibitor tumor necrosis factor receptor-1 and CD-95-induced apoptosis. J. Biol. Chem. 272: $17255-17257$

6. Shu HB, Halpin DR and Goeddel DV (1997) Casper is a FADD- and caspaserelated inducer of apoptosis. Immunity 6: 751-763

7. Srinivasula SM, Ahmad M, Ottlie $S$, Bullrich $F$, Banks $S$, Wang $Y$, FernandesAlnemri T, Croce CM, Litwack G, Tomaselli KJ, Armstrong RC and Alnemri ES (1997) FLAME-1, a novel FADD-like anti-apoptotic molecule that regulates Fas/TNFR1-induced apoptosis. J. Biol. Chem. 272: 18542-18545

8. Inohara N, Koseki T, Hu Y, Chen S and Nunez G (1997) CLARP, a death effector domain-containing protein interacts with caspase-8 and regulates apoptosis. Proc. Natl. Acad. Sci. USA 94: 10717-10722

9. Han DK, Chaudhary PM, Wright ME, Friedman C, Trask BJ, Riedel RT, Baskin DG, Schwartz SM and Hood L (1997) MRIT, a novel death-effector domaincontaining protein, interacts with caspases and $\mathrm{Bc} \mathrm{XL}$ and initiates cell death. Proc. Natl. Acad. Sci. USA 94: 11333-11338

10. Thome M and Tschopp J (2001) Regulation of lymphocyte proliferation and death by FLIP. Nat. Rev. Immunol. 1: 50-58

11. Krueger A, Baumann S, Krammer PH and Kirchhoff S (2001) FLICE-inhibitory proteins: regulators of death receptor-mediated apoptosis. Mol. Cell. Biol. 21: 8247-8254

12. Budd RC (2002) Death receptors couple to both cell proliferation and apoptosis. J. Clin. Invest. 109: 437-441

13. Newton K, Harris AW, Bath ML, Smith KGC and Strasser A (1998) A dominant interfering mutant of FADD/MORT1 enhances deletion of autoreactive thymocytes and inhibits proliferation of mature T lymphocytes. EMBO J. 17: $706-718$

14. Walsh CM, Wen BG, Chinnaiyan AM, O'Rourke K, Dixit VM and Hedrick SM (1998) A role for FADD in T cell activation and development. Immunity 8: 439-449

15. Zhang J, Cado D, Chen A, Kabra NH and Winoto A (1998) Fas-mediated apoptosis and activation-induced T-cell proliferation are defective in mice lacking FADD/Mort1. Nature 392: 296-300

16. Zornig M, Hueber AO and Evan G (1998) p53-dependent impairment of T-cell proliferation in FADD dominant-negative transgenic mice. Curr. Biol. 8: $467-470$ 
17. Newton K, Kurts C, Harris AW and Strasser A (2001) A dominant interfering mutant of FADD/MORT1 enhances deletion of autoreactive thymocytes and inhibits proliferation of mature T lymphocytes. Curr. Biol. 11: 273-276

18. Zhang J, Kabra NH, Cado D, Kang $C$ and Winoto $A$ 2001) FADD-deficient $T$ cells exhibit a disaccord in regulation of the cell cycle machinery. J. Biol. Chem. 276: 29815-29818

19. Mack A and Hacker $G$ (2002) Inhibition of caspase or FADD function blocks proliferation but not MAP kinase-activation and interleukin-2-production during primary stimulation of T cells. Eur. J. Immunol. 32: 1986-1992

20. Hua ZC, Sohn SJ, Kang C, Cado D and Winoto A (2003) A function of Fasassociated death domain protein in cell cycle progression localized to a single amino acid at its C-terminal region. Immunity 18: 513-521

21. Kennedy NJ, Kataoka T, Tschopp J and Budd RC (1999) Caspase activation is required for T cell proliferation. J. Exp. Med. 190: 1891-1895

22. Boissonnas $A$, Bonduelle $\mathrm{O}$, Lucas $\mathrm{B}$, Debr $\mathrm{P}$, Autran $\mathrm{B}$ and Combadière $\mathrm{B}$ (2002) Differential requirement of caspases during naive $T$ cell proliferation. Eur. J. Immunol. 32: 3007-3015

23. Chun HJ, Zheng L, Ahmad M, Wang J, Speirs CK, Siegel RM, Dale JK, Puck J, Davis J, Hall CG, Skoda-Smith S, Atkinson TP, Straus SE and Lenardo MJ (2002) Pleiotropic defects in lymphocyte activation caused by caspase-8 mutations lead to human immunodeficiency. Nature 419: 395-399

24. Salmena L, Lemmers B, Hakem A, Matysiak-Zablocki E, Murakami K, Au PYB, Berry DM, Tamblyn L, Shehabeldin A, Migon E, Wakeham A, Bouchard D, Yeh WC, McGlade JC, Ohashi PS and Hakem R (2003) Essential role for caspase 8 in T-cell homeostasis and T-cell-mediated immunity. Genes Dev. 17: 883-895

25. Newton K and Strasser A (2003) Caspases signal not only apoptosis but also antigen-induced activation in cells of the immune system. Genes Dev. 17: 819-825

26. Van Parijs L, Refaeli Y, Abbas AK and Baltimore D (1999) Autoimmunity as a consequence of retrovirus-mediated expression of c-FLIP in lymphocytes. Immunity 11: 763-770

27. Lens SM, Kataoka T, Fortner KA, Tinel A, Ferrero I, MacDonald RH, Hahne M, Beermann F, Attinger A, Orbea HA, Budd RC and Tschopp J (2002) The caspase 8 inhibitor C-FLIP $(L)$ modulates T-cell receptor-induced proliferation but not activation-induced cell death of lymphocytes. Mol. Cell. Biol. 22: 54195433

28. Kataoka T, Budd RC, Holler N, Thome M, Martinon F, Irmler M, Burns K, Hahne M, Kennedy N, Kovacsovics M and Tschopp J (2000) The caspase-8 inhibitor FLIP promotes activation of NF- $\kappa \mathrm{B}$ and Erk signaling pathways. Curr. Biol. 10: 640-648

29. Zhumabekov T, Corbella P, Tolaini M and Kioussis D (1995) Improved version of a human CD2 minigene based vector for $T$ cell-specific expression in transgenic mice. J. Immunol. Methods 185: 133-140
30. Brunner T, Mogil RJ, LaFace D, Yoo NJ, Mahboubl A, Echeverri F, Martin SJ, Force WR, Lynch DH, Ware CF and Green DR (1995) Cell-autonomous Fas(CD95)/Fas-ligand interaction mediates activation-induced apoptosis in T-cell hybridomas. Nature 373: 441-444

31. Dhein J, Walczak H, Baumler C, Debatin KM and Krammer PH (1995) Autocrine T-cell suicide mediated by APOI-1(Fas/CD95). Nature 373: $438-441$

32. Ju ST, Panka DJ, Cui H, Ettinger R, El-Khatib M, Sherr DH, Stanger BZ and Marshak-Rothstein A (1995) Fas(CD95)/FasL interactions required for programmed cell death after T-cell activation. Nature 373: 444-448

33. Vignaux F, Vivier E, Malissen B, Depraetere V, Nagata S and Golstein P (1995) TCR/CD3 coupling to Fas-based cytotoxicity. J. Exp. Med. 181: 781-786

34. OhYama T, Tsukumo S, Yajima N, Sakamaki K and Yonehara S (2000) Reduction of thymocyte numbers in transgenic mice expressing viral FLICEinhibitory protein in a Fas-independent manner. Microbiol. Immunol. 44: 289-297

35. Bouillet P, Purton JF, Godfrey DI, Zhang LC, Coultas L, Puthalakath H, Pellegrini M, Cory S, Adams JM and Strasser A (2002) BH3-only Bcl-2 family member Bim is required for apoptosis of autoreactive thymocytes. Nature 415 : 922-926

36. Hildeman DA, Zhu Y, Mitchell TC, Bouillet P, Strasser A, Kappler J and Marrack $\mathrm{P}$ (2002) Activated T cell death in vivo mediated by proapoptotic bcl-2 family member bim. Immunity 16: 759-767

37. Chang DW, Xing Z, Pan Y, Algeciras-Schimnich A, Barnhart BC, Yaish-Ohad $S$, Peter ME and Yang X (2002) C-FLIP is a dual function regulator for caspase-8 activation and CD-95-mediated apoptosis. EMBO J. 21: 3704-3714

38. Micheau O, Thome M, Schneider P, Holler N, Tschopp J, Nicholson DW, Briand C and Grütter MG (2002) The long form of FLIP is an activator of caspase-8 at the Fas death-inducing signaling complex. J. Biol. Chem. 277: 45162-45171

39. Yeh WC, Itie A, Elia AJ, Ng M, Shu HB, Wakeham A, Mirtsos C, Suzuki N, Bonnard M, Goeddel DV and Mak TW (2000) Requirement for Casper (c-FLIP) in regulation of death receptor-induced apoptosis and embryonic development. Immunity 12: 633-642

40. Liu L, Eby MT, Rathore N, Sinha SK, Kumar A and Chaudhary PM (2002) The human herpes virus 8-encoded viral FLICE inhibitory protein physically associates with and persistently activates the $\mathrm{I}_{\kappa} \mathrm{B}$ kinase complex. J. Biol. Chem. 277: 13745-13751

41. Yeh JH, Hsu SC, Han SH and Lai MZ (1998) Mitogen activated kinase kinase antagonized FADD-mediated apoptosis by induced FLIP expression. J. Exp. Med. 188: 1795-1802

42. Nicoletti I, Migliorati G, Pagliacci MC, Grignani F and Riccardi C (1991) A rapid and simple method for measuring thymocyte apoptosis by propidium iodide staining and flow cytometry. J. Immunol. Methods 139: 271-279 